\title{
A study on relationship between emotional intelligence and organizational indifference through the organizational commitment: A case study of an Iranian firm
}

\author{
Hafez Mollaabbasi*, Behrooz Rezaeemanesh and Jamshid Salehi Sadaghiani
}

Department of Management, Allameh TabaTabayi University Tehran, Iran

\begin{tabular}{l}
\hline C H R O N I C L E \\
\hline Article history: \\
Received January 14, 2013 \\
Received in revised format \\
18 April 2013 \\
Accepted 20 April 2013 \\
Available online \\
April 222013 \\
\hline Keywords: \\
Emotional intelligence \\
Organizational commitment \\
continuous commitment \\
Normative commitment \\
Affective commitment \\
Organizational indifference
\end{tabular}

A B S T R A C T

This research surveys the relationship between emotional intelligence and organizational indifference through a commitment. The study first presents theoretical models over the investigation then six hypotheses are developed based on the conceptual model for this opinion. Questionnaire contains 16 questions for organizational indifference and 20 questions for organizational commitment and 23 questions for emotional intelligence. The Cronbach's alpha of organizational indifference questionnaire is 0.938 and the Cronbach's alpha of organizational commitment questionnaire is equal to 0.802 and Emotional Intelligence questionnaire reliability coefficient is 0.961 . Both questionnaires maintain sufficient reliability because their Cronbach alphas are more than 0.7. The sample size is chosen according KREJCIE and Morgan table and is equal to 235 people. Kolmongrov - Smirnov test is used for normality of the obtained data. Research hypothesis and the correlations between variables are tested by Spearman correlation test. The results imply approval of all research hypotheses and significant relationship between emotional intelligence and organizational indifference.

(C) 2013 Growing Science Ltd. All rights reserved.

\section{Introduction}

During the past few years, there have been many studies on relationship between emotional intelligence and organizational indifference. According to Mahmoodi Meimand et al. (2012), one of the results of intention to human force is to build a phenomenon called "organizational indifference" where we face a working-cycle (Cho et al., 2005). When people select a new job or gain promotion authority in organization, they encounter a situation rich in motive and passion and they are getting excited about people who are about to work with. In such circumstances, employee may feel that they have been given a position playing an essential role within firm. Problem happens after this stage where people's opinions change steadily, and their motive and passion are replaced with organizational indifference. The employees and management's silence and discouragement are serious danger to reduce organizational performance, which damage all society in a greater level.

\footnotetext{
Corresponding author.

E-mail: hafez_88m@yahoo.com (H. Mollaabbasi)

(C) 2013 Growing Science Ltd. All rights reserved. doi: $10.5267 /$ j.msl.2013.04.022
} 
Lemmergaard and Louise Muhr (2012) explained how dis-identification collapses among Danish correctional officers because of specific emotional contradictions occurs from the 'dirty' perspectives of their work. Correctional officers encounter the emotional dilemma of having to both get involved with the inmates to rehabilitate them and be suspicious of them to keep security. They also have to deal with the stigma of their job and cannot easily vent their emotional experiences with many outsiders. It therefore becomes tedious task to uphold a positive and coherent sense of self. Peachey and Bruening (2012) investigated ambivalence towards organizational change in a Football Championship Subdivision intercollegiate athletic department. They stated that ambivalence was a salient response to some change, and intrapersonal conflict, perceived lack of institutional support, managerial turnover, and previous negative experience with change could be served as antecedents.

Spillan, J., \& Hough, M. (2003) investigated crisis planning in a survey of small businesses. It specifically concentrated on the perceived importance of crisis planning by some small business managers. They investigated whether the experience of an actual crisis event by a business creates concern for future crises, if concern is generated more from a crisis event or from a crisis management team. They reported that crisis planning received little attention in the small businesses surveyed and found that even those businesses that had previously experienced crises did not have any crisis management teams. Willemsen and Keren (2003) examined the matching procedure and demonstrated inconsistencies within the method itself.

Amir Khani et al. (2013) presented an empirical investigation to investigate the impact of spiritual on empowering employees of Payame Noor university in city of Tehran, Iran. They applied two benchmark questionnaires to investigate the hypotheses of this survey. There were various subhypotheses associated with this study including the relationship between empowering employees from one side and vision, being meaningful, organizational membership, organizational commitment, faith to work, friendship and performance feedback. The results of implementation of structural equation modeling confirmed all sub-hypotheses except commitment.

Esfahani et al. (2013) investigated the relationship between job involvement and organizational commitment among lower-level employees in Iranian automaker industry. In their study, job involvement was an independent variable, organizational commitment was dependent variable, and the analysis was performed using 100 randomly selected data through a questionnaire. They gathered biographical and occupational data using a self-designed 40-item questionnaire. The study used various statistical techniques including Pearson Product Moment Correlation Technique and Multiple Regression Analysis. The results indicated that job involvement was strongly associated with organizational commitment.

Saeidipour (2013) performed an empirical investigation on the effect of organizational climate on organizational commitment using a case study of educational system. The study detected the impact of organizational climate on level of organizational commitment among staff education in city of Kermanshah located in west part Iran. They showed that there was a significant relationship between the components of role and paying enough attention to goals, the variable organizational climate, and the whole variable dimensions of organizational commitment. The other observation was that there was a weak relationship with some components of social commitment, and there was not any significant relationship with other aspects. The results of multivariate regression analysis also indicated that there was a high correlation between organizational climate and social commitment.

Keramati et al. (2013) investigated the relationship between six personal characteristics of employees of Azad University in province of Arak, Iran. The proposed study designed and distributed a questionnaire among experts who were involved in education systems. The population of this survey includes 900 employees who were enrolled in educational as well as administration levels and chooses a sample of 269 people for the survey. They studied the relationship of these six items with organization commitment and reported that marital status was the most influential factor on 
organizational commitment followed by educational background and job experience. They concluded that those employees who could get more experience and maintain a good educational background would more likely to stay with a firm than young employees.

Azad and Sadeghi (2012) gathered the necessary information from 200 employees who worked for custom organization in Iran. The results of factor analysis indicated there were four factors influencing organizational commitments. The first factor was associated with cultural factor, the second issue was related to human resource based factors while the third factor indicates the behavior based factors and finally empowering based factors are the last item.

Abid et al. (2012) explored the authentic leadership styles of an entrepreneurs and its effect on employee's commitment and satisfaction. The study tried to give a tentative test of the connection among employees' awareness of the business creator as an authentic leader and the employees' attitudes using the authentic leadership model. They reported that the opinion of employees' about authentic leadership serves as the intoxicating analyst of employee job satisfaction and organizational commitment.

\section{Background research}

\subsection{The main hypothesis}

The main hypothesis of this survey investigates whether there is any significant relationship between emotional intelligence through organizational commitment and organizational Indifference or not.

\subsubsection{Secondary research hypotheses}

The following five hypotheses are associated with the proposed study of this paper.

Hypothesis 1: There is relationship between emotional intelligence and organizational commitment.

Hypothesis 2: There is relationship between Organizational commitment and organizational indifference.

Hypothesis 3: There is relationship between Emotional intelligence and affective commitment.

Hypothesis 4: There is relationship between Emotional intelligence and the commitment continuity.

Hypothesis 5: There is relationship between Emotional intelligence and normative commitment.

\subsection{Population and sampling}

The study population consists of 600 employees and associates system. In this study, simple random sampling method was used according the distribution of population, the volume of sample selected from the community by using Cochran's formula for the number of 235 people by using a questionnaire and then the information has been gathered and analyzed.

\subsection{Methods of data analysis}

For both descriptive and inferential analysis, data analysis procedure is as follows. Inferential statistics to test the "Kolmogorov - Smirnov" to check the normality of data distribution and the Spearman correlation test was used to test the research hypotheses. Descriptive statistics for demographic variables shows that $67 \%$ of them were men and $32 \%$ of them were women. In terms of educational background, $0.5 \%$ of the participants hold $\mathrm{PhD}$ degree, $41.5 \%$ of them had master degree, $47 \%$ of them had bachelor's degree and $6.5 \%$ of them hold associate's degree. Therefore, we can conclude that nearly half of respondents had a bachelor's degree. About $50 \%$ of them were 30 to 35 years old. In order to determine the type of test used to investigate the hypotheses, we first need to 
review our assumptions of normality or non-normality of the data, using parametric or nonparametric test results of the statistical methods used for testing hypotheses said. Table 1 shows the results of Kolmogorov - Smirnov normality test.

\section{Table 1}

Test of the Kolmogorov - Smirnov

\begin{tabular}{lcccc}
\hline $\begin{array}{l}\text { Distributed observations follow a normal distribution. } \\
\text { Observed distribution does not follow a normal distribution. }\end{array}$ & \multicolumn{3}{c}{$\begin{array}{l}\mathrm{H}_{0}: \mathrm{P}=0 \\
\mathrm{H}_{1}: \mathrm{P} \neq 0\end{array}$} \\
\hline Variable & Samples & Test statistic & Value sig & Test \\
\hline Emotional Intelligence & 235 & 4.384 & 0.00 & Non-normal distribution \\
Organizational commitment & 235 & 5.029 & 0.00 & Non-normal distribution \\
Incuriosity & 235 & 4.673 & 0.00 & Non-normal distribution \\
Normative commitment & 235 & 5.835 & 0.00 & Non-normal distribution \\
Ongoing commitment & 235 & 5.18 & 0.00 & Non-normal distribution \\
Affective commitment & 235 & 5.095 & 0.00 & Non-normal distribution \\
\hline
\end{tabular}

As can be seen from the results of Table 1, the results of Kolmogorov - Smirnov test indicates that none of the variables is normally distributed. Table 2 shows details of the implementation of Spearman test.

\section{Table 2}

Spearman correlation test results for hypotheses

\begin{tabular}{lllll}
\hline & & $\begin{array}{l}\text { Emotional } \\
\text { Intelligence }\end{array}$ & $\begin{array}{l}\text { Organizational } \\
\text { commitment }\end{array}$ & $\begin{array}{l}\text { Institutional } \\
\text { indifference }\end{array}$ \\
\hline The correlation coefficient & Emotional Intelligence & 1 & 0.26 & -0.293 \\
Level of significance & & 0.00 & 0.00 & 0.00 \\
Number & & 235 & 235 & 235 \\
\hline The correlation coefficient & Organizational commitment & 0.26 & 1 & -0.553 \\
Level of significance & & 0.00 & 0.00 & 0.00 \\
Number & & 235 & 235 & 235 \\
\hline The correlation coefficient & Institutional indifference & -0.293 & -0.553 & 1 \\
Level of significance & & 0.00 & 0.00 & 0.00 \\
Number & & 235 & 235 & 235 \\
\hline & & Normative & Ongoing & Affective \\
& & commitment & commitment & commitment \\
\hline The correlation coefficient & Emotional Intelligence & 0.209 & 0.212 & 0.116 \\
Level of significance & & 0.001 & 0.001 & 0.00 \\
\hline The correlation coefficient & Institutional indifference & -0.091 & -0.037 & -0.449 \\
Level of significance & & 0.165 & 0.57 & 0.00 \\
\hline
\end{tabular}

\section{The results}

In this section, we present details of our findings on testing various hypotheses using Pearson correlation test.

\subsection{The sub-hypotheses}

We first present details of our sub-hypotheses.

\subsubsection{The first hypothesis: Emotional intelligence and organizational commitment}

The first hypothesis of this survey investigates the relationship between emotional intelligence and organizational commitment. The results of inferential statistics in Table 2 show that there are some 
significant relationship between emotional intelligence and organizational commitment in the Hamkaran system. The correlation coefficient between emotional intelligence and organizational commitment is 0.26 , which shows the coefficients obtained in the EI system partners in improving organizational commitment is involved.

\subsubsection{The second hypothesis: Organizational commitment and organizational indifference}

The second hypothesis of this survey studies the relationship between organizational commitment and organizational indifference. The results of inferential statistics in Table 2 show that there is a significant relationship between organizational commitment and organizational indifference in Hamkaran Systems. The correlation coefficient correlation between organizational commitment and organizational indifference is -0.553 . This ratio is obtained and shows the organization's commitment to corporate organizational indifference is inversely related to the Hamkaran system.

\subsubsection{The third hypothesis: Emotional intelligence and emotional commitment}

The results of inferential statistics in Table 2 show that there is significant relationship between emotional intelligence and emotional commitment in the Hamkaran system. The correlation coefficient between emotional intelligence and emotional commitment is 0.116 . The index shows that emotional intelligence is involved in the Hamkaran system in affective commitment.

\subsubsection{The fourth hypothesis: emotional intelligence and ongoing commitment}

The fourth hypothesis is associated with emotional intelligence and ongoing commitment. The results of inferential statistics in Table 2 show that there is a significant correlation between the company's ongoing commitment and emotional intelligence in Hamkaran system. The correlation coefficient between emotional intelligence and continuous commitment is 0.212 . This coefficient is obtained and shows the continuing commitment by the Hamkaran system are involved in emotional intelligence

\subsubsection{The fifth hypothesis: The relationship between emotional intelligence and normative commitment}

The results of inferential statistics in Table 2 show that there is a significant correlation between emotional intelligence and normative commitment to the Hamkaran system. The correlation coefficient between emotional intelligence and normative commitment is 0.209 . This shows the coefficients obtained in the Hamkaran system are involved in normative commitment

\subsection{The main hypothesis}

The results of inferential statistics in Table 2 show that there is a significant relationship between emotional intelligence and organizational indifference in the Hamkaran system. The correlation coefficient between emotional intelligence and organizational commitment is -0.293 . This ratio is obtained and shows the emotional intelligence is inversely related to the institutional organizational indifference in Hamkaran system. The results of inferential statistics in Table 2 indicate all relationships are significant errors in the 0.05 and therefore all research hypotheses were confirmed with $95 \%$ certainty.

\section{Conclusion}

We have examined the relationship between emotional intelligence and organizational commitment on organizational indifference in Hamkaran Systems. During the investigation, it was stated that a major factor exists in the quality of products and services for corporate indifference organizations. Therefore, with the current state of organizational indifference about the organization, emotional 
intelligence and organizational commitment variables of this study have significant negative relationship between emotional intelligence and organizational indifference through organizational commitment in Hamkaran Systems. Therefore, research hypothesis was confirmed when the level of significance is $5 \%$. Therefore, the managers who are looking to improve employee performance in their organization should go through altruism, emotional intelligence, work ethics, generosity, courtesy and their strategic value to the organization. System managers who increase the level of organizational commitment in this regard can empower staff recruitment and hiring competent.

\section{References}

Abid, T., Altaf, M., Yousaf, U., \& Mehmood Bagram, M.M. (2013). Entrepreneur as an authentic leader: A study of small and medium sized enterprises in Pakistan. Management Science Letters, 2(7), 2355-2360.

Amir Khani, A.H., Darvish, H., Miandari, K., \& Sotudeh Arani, H. (2013). The role of spiritual leadership on empowering employees: A case study of educational system. Management Science Letters, 3(3), 1013-1018.

Azad, N., \& Sadeghi, S. (2012). An empirical study to determine effective factors on organizational commitment. Management Science Letters, 2(8), 2981-2986.

Cho, Y.H., Truong, L., \& Haneda, M. (2005). Testing the indifference between a binary lottery and its edited components using observed estimates of variability. Organizational Behavior and Human Decision Processes, 97(1), 82-89.

Esfahani, M.J., Emami, M., \& Tajnesaei, H.R. (2013). The investigation of the relation between job involvement and organizational commitment. Management Science Letters, 3(2), 511-518.

Keramati, M.A., Horri, M.S., \& Afzalipoor, S.H.R. (2013). A study on effects of personal characteristics on organizational commitment. Management Science Letters, 3(1), 345-350.

Mahmoodi Meimand, M., Aidi, M., Shiri, A., \& Darabifar, H. (2012). Effect of Organization Indifference Dimensions on the Organizational Commitment of Gas Company Employees in Ilam Province. Procedia - Social and Behavioral Sciences, 62, 666-667.

Lemmergaard, J., \& Louise Muhr, S. (2012). Golfing with a murderer-Professional indifference and identity work in a Danish prison. Scandinavian Journal of Management, 28(2), 185-195.

Peachey, J.W., \& Bruening, J. (2012). Investigating ambivalence towards organisational change in a Football Championship Subdivision intercollegiate athletic department. Sport Management Review, 15(2), 171-186.

Saeidipour, B. (2013). A study on the effect of organizational climate on organizational commitment: A case study of educational system. Management Science Letters, 3(1), 181-194.

Spillan, J., \& Hough, M. (2003). Crisis planning in small businesses:: Importance, Impetus and Indifference. European Management Journal, 21(3), 398-407.

Willemsen, M.C., \& Keren, G. (2003). The meaning of indifference in choice behavior: Asymmetries in adjustments embodied in matching. Organizational Behavior and Human Decision Processes, 90(2), 342-359. 